\title{
MYKOLA GRYGOROVYCH NAKHODKIN
}

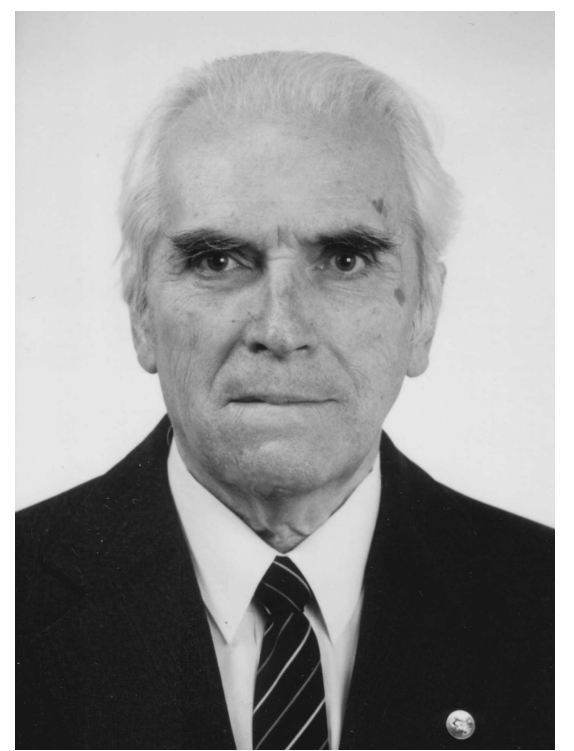

On January 25, 2015, Mykola Grygorovych Nakhodkin, an outstanding Ukrainian scientist and physicist, Academician of the National Academy of Sciences of Ukraine (NASU), the Honored worker in science and engineering, the winner of the State Prizes of Ukraine in science and engineering is 90 years old.

M.G. Nakhodkin was born at the village of Prokhorivka near Kaniv, in doctor's family. Prokhorivka is known to be a place where, in the middle of the 19th century, there was a manor of M.O. Maksymovych, the first rector of the Kyiv University.

The whole professional activity of Mykola Grygorovych is inseparably linked with the Taras Shevchenko Kyiv University. After graduating from its Faculty of Physics in 1950, he entered the postgraduate course and, in 1954, defended the Ph. D. thesis entitled "Research of secondary emission in some metals and semiconductors". N.D. Morgulis, Corresponding Member of the Academy of Sciences of the UkrSSR (AS UkrSSR), the founder of the Kyiv scientific school of physical electronics, was a supervisor of his work. In 1966, Mykola Grygorovych defended his thesis for the Doctoral degree entitled "Interaction of electrons and soft X-rays with a thin-layer substance". In 1973, he was elected Corresponding Member of the AS UkrSSR and, in 1990, Academician of the AS UkrSSR in the speciality "Radiophysics".

ISSN 2071-0194. Ukr. J. Phys. 2015. Vol. 60, No. 1
As early as in 1952, M.G. Nakhodkin started to lecture at the Chair of Electronics headed by N.D. Morgulis. The same year, the Faculty of Radiophysics was created on the basis of this chair.

In 1972, M.G. Nakhodkin organized the Chair of Cryogenic and Microelectronics (now, the Chair of Nanophysics and Nanoelectronics) at the Faculty of Radiophysics and headed it for 26 years. On his initiative, two scientific laboratories (the Laboratory of electron spectroscopy and the Laboratory of optical information processing and the theory of media) were created at the chair. Chair's branch on the basis of S.P. Korolev Kyiv production association was organized in 1981, and Chair's branch on high-temperature superconductivity on the basis of the Institute of Metal Physics of the AS UkrSSR was establisned in 1989.

In 1972, M.G. Nakhodkin was elected the Dean of the Faculty of Radiophysics (since 2014, the Faculty of Radiophysics, Electronics, and Computer Systems) of the T.G. Shevchenko Kyiv State University (now, the Taras Shevchenko National University of Kyiv). He held this position for 19 years. As a leader, he created a highly efficient team of like-minded persons, which included, in particular, his deputies P.S. Kuts and P.V. Mel'nyk, the heads of chairs D.O. Gorodets'kyi, V.V. Danylov, S.M. Levyts'kyi, V.I. Strikha, and Yu.I. Chutov. He initiated the creation of the Chair of Medical Radiophysics at the Faculty of Radiophysics (the chair was headed by Mykola Grygorovych's disciple M.K. Novoselets) and a special faculty dealing with retraining in functional electronics and high-temperature superconductivity. Leading experts of the AS UkrSSR were engaged to lecture at the faculty, in particular, Academicians V.G. Bar'yakhtar, M.S. Brodyn, and A.G. Naumovets, Corresponding members M.O. Krivoglaz, V.G. Litovchenko, E.G. Petrov, S.M. Ryabchenko, M.S. Soskin, P.I. Fomin, and M.K. Sheinkman. The work style and the traditions of the faculty formed at that time survived, to a great extent, till now.

The professional interests of Mykola Grygorovych always concentrated around science. The start of his scientific carrier was connected with studying the secondary electron emission in thin layers of metals and semiconductors. This activity was aimed at de- 
veloping the efficient emitters; it was an extremely important problem for vacuum and gas electronics, which constituted the basis of radioelectronics on the whole at that time. M.G. Nakhodkin also dealt with oxide cathodes (together with G.O. Zykov). Later, also in collaboration wuth G.O. Zykov, he created a laser mass-spectrometer, the unique tool allowing the composition of small amounts of substances to be analyzed. As an example, by using this device, the authenticity of Kyiv glagolic sheets, the well-known monument of the ancient Slavonic written language, was proved.

The next stage in the scientific activity of M.G. Nakhodkin was the research of the electron emission from thin films stimulated by soft x-ray radiation. Mykola Grygorovych pioneered in the study of differential characteristics (spectra) of both secondary electron and x-ray photoelectron emission (together with P.V. Mel'nyk). Simultaneously, he began a large cycle of works devoted to the research of thermoplastics and the development of methods for recording information on non-silver carriers (together with M.G.Kuvshyns'kyi). In 1962-1995, he carried out the researches of fundamental regularities in the surface mass transfer and the kinetics of electronic processes on the surface and in the near-surface layers of solids. Distinctions of transport phenomena on the surface and in the bulk of the solid and their physical origin were determined.

Requirements for the development of microelectronics stimulated a cycle of Nakhodkin's works on the thin film structure, in particular, its dependence on growing conditions. The coauthors of those works were A.I. Novosels'ka and O.F. Bardamid. The corresponding publication remains one of the most cited ones in the scientific contribution of Mykola Grygorovych.

The development of methods of solid surface diagnostics required a detailed study of the mean free path of an electron owing to its inelastic interaction with the electron subsystem of the surface. The corresponding researches were carried out by M.G. Nakhodkin together with Yu.M. Kryn'ko, D.I. Sheka, and O.M. Voskoboinikov in 1980-1990.

From the beginning of the 1980s, Mykola Grygorovych together with I.P. Koval developed a new experimental method for the diagnostics of a solid surface, ionization spectroscopy, which now occupies a worthy place in the arsenal of research tools.
In the mid-1990s, M.G. Nakhodkin together with I.V. Lyubynets'kyi created a ultra-high vacuum tunneling microscope with atomic resolution, which was the first in Ukraine. With the help of this tool and in collaboration with S.Yu. Bulavenko, he studied, for the first time, fine details in the arrangement of hydrogen atoms adsorbed on the silicon surface.

Mykola Grygorovych supervised the teams of Ukrainian physicists, who worked in the framework of the program "Physicochemical, structural, and emission properties of thin films and solid surface". For a long time, together with the Nobel winner Zh.I. Alferov, he had been heading the Ukrainian-Russian scientific program in nanoelectronics.

In 1970, M.G. Nakhodkin became a winner of the State Prize of the UkrSSR in science and engineering for the cycle of works dealing with the information recording on thermoplastics. In 1997, he was awarded the State Prize of Ukraine in science and engineering for a cycle of works devoted to a number of new effects on the solid surface, in particular, the interference of the elastic and inelastic scattering channels for medium-energy electrons. Their application made it possible to develop new methods for surface diagnostics.

The long-term scientific activity of Mykola Grygorovych resulted in the formation of a scientific school "Emission electronics and electron spectroscopy" headed by him. It continued the traditions of N.D. Morgulis' school of physical electronics. Now, the corresponding scope of researches includes the processes of interaction of electrons and ultra-violet and soft x-ray radiation quanta with the solid, secondary electron emission, electron spectroscopy, mass-spectrometry, formation of thin film structures, thermionic emission of semiconductors and oxide cathodes, tunneling scanning microscopy, and nanostructure diagnostics.

The scientific contribution of M.G. Nakhodkin consists of more than 350 scientific publications and 41 author's certificates. He was the coauthor and the editor of 3 monographs. ${ }^{1}$

\footnotetext{
${ }^{1}$ Lasers in Criminalistics and Forensic Examination, edited by N.G. Nakhodkin and V.I. Goncharenko (Vyshcha Shkola, Kyiv, 1986) (in Russian); Atlas of Ionization Spectra, edited by N.G. Nakhodkin (Vyshcha Shkola, Kyiv, 1989) (in Russian); and Ionization Spectroscopy, edited by N.G. Nakhodkin (Lybid', Kyiv, 1992) (in Russian).
} 
M.G. Nakhodkin puts much effort and energy into the scientific-managerial activity. He is able to think at the state level rather than the level of a separate scientific or educational institution. Mykola Grygorovych was one of the initiators of creation and the chairman of the National Science and Technology Council of Ukraine, one of the founders and the first president of the Ukrainian Committee of the International Union of Radio Science (the URSI branch). For 6 years, M.G. Nakhodkin had been the vice-president of the scientific and technical council of the Ministry of higher and secondary special education of the UkrSSR (order No. 323 of 12.09.1978), a member of a section of the Committee on State Prizes of Ukraine (from 1973), the chairman of a section and a member of the presidium of this committee (from 1981), a member of the Chief Council of the Higher Attestation Commission of the Cabinet of Ministers of Ukraine (order No. 1 of 04.01.1993), the chairman and a member of the Expert Council of the Higher Attestation Commission of Ukraine. M.G. Nakhodkin is a member of the editorial board of the Ukrainian Journal of Physics; he was a member of the editorial boards of the Journal of scientific and applied photoand cinematography (the edition of the AS of the USSR), the collections of works Quantum electronics, Physics of semiconductors and insulators, Physical electronics, the journal Bulletin of Kyiv University (till 1990). He was a founder and the editor-in-chief (for 20 years) of the interdepartmental collection of works Fundamentals of optical memory and media.

Mykola Grygorovych was a member of the scientific councils on physical electronics and holography of the AS of the USSR and several sections of the AS UkrSSR. He was a scientific supervisor in a number of interdepartmental scientific programs and the programs of the Ministry of Education of Ukraine. At present, he is a member of the presidium of the Division of Physics and Astronomy of the NASU.

As a lecturer, Mykola Grygorovych can make even the most complicated issue clear for students. He constructs the educational process on the basis of scientific work. In this aspect, he develops traditions started by N.D. Morgulis. For several decades, he is lecturing the general course "Atomic physics" and the special course "Physical bases of microelectronics". At various periods, he also lectured the special courses "Electricity", "Optics", "Physical electronics" (for the students of the Chair of Semiconductor Physics; this course was specially prepared by M.G. Nakhodkin at the request of Academician V.E. Lashkarev, the Head of the chair at that time), "Calculation of electron lenses", "Electron optics", and "Thin film physics". Lecturer's huge experience was embodied by M.G. Nakhodkin in 3 textbooks ${ }^{2}$ and 2 manuals $^{3}$, which are very popular among his students and colleagues.

M.G. Nakhodkin pays much attention to the training of a high-skilled staff, works with young scientists at the faculty, as well as with those from other regions of Ukraine and CIS countries. Among his disciples, there are 5 Doctors of Science and 29 Ph.Ds, the winners of the State Prizes of Ukraine in science and engineering.

The merits of Mykola Grygorovych were marked by the order "Sign of Honor" and medals, the Certificates of honor of the Presidium of the Supreme Council of the UkrSSR and the Supreme Council of Ukraine (in 2002), the Certificate of honor of the Cabinet of Ministers of Ukraine (in 2004), the order "For merits" II and III degree, and the honorable distinction of the NASU. In 1995, Mykola Grygorovych was ranked the Honored worker in science and engineering. In 1999, he became the Honored Professor of the Taras Shevchenko National University of Kyiv. In 1989, one of the small planets was named after him (8065 Nakhodkin=1979 FD3).

Mykola Grygorovych is a very strong wise person, excellent leader, manager, and bearer of high moral qualities.

We wish to Mykola Grygorovych Nakhodkin sound health, creative inspiration, success in his work, and worthy disciples.

\footnotetext{
2 M.G. Nakhodkin and D.I. Sheka, Physical Bases of Microand Nanoelectronics (Kyiv Univ. Publ. Center, Kyiv, 2005) (in Ukrainian); M.G. Nakhodkin and F.F. Syzov, Elements of Functional Electronics (VPF UkrINTEI, Kyiv, 2002) (in Ukrainian); and M.G. Nakhodkin and N.P. Kharchenko, Atomic Physics (Kyiv Univ. Publ. Center, Kyiv, 2012) (in Ukrainian).

${ }^{3}$ M.G. Nakhodkin, A.G. Naumovets, and S.M. Ryabchenko, For Those Who Break Their Way to Science (Kyiv University Publishing Center, Kyiv, 2008) (in Ukrainian); M.G. Nakhodkin, P.V. Mel'nyk, and A.O. Goloborod'ko, Problems to the Course of Physical Bases of Micro- and Nanoelectronics (Kyiv Univ. Publ. Center, Kyiv, 2014) (in Ukrainian)
} 